\title{
The Construction of Educational Community based on the Technology of Internet plus Satellite Live Broadcasting
}

\author{
Song Han
}

No.1 Middle School of Zhengzhou, Zhengzhou 450006, Henan, China

\begin{abstract}
In the current climate of pursuing educational equity, the construction of educational community is a worthwhile experiment in achieving equitable development of urban and rural education. Establishing a multi-channel cooperation mechanism between urban and rural schools and giving full play to the existing highquality educational resources are feasible and efficient ways to reach quality and equity education. Based on the technology of Internet plus satellite live broadcasting and its own resource advantages, No.1 Middle School of Zhengzhou constructed an educational community across time and space, which effectively promotes balanced development of education in the region and has enhanced the overall educational level there.
\end{abstract}

Science Insights Education Frontiers 2021; 10(2):1451-1459.

Doi: 10.15354/sief.21.or067

How to Cite: Han, S. (2021). The construction of educational community based on the technology of internet plus satellite live broadcasting. Science Insights Education Frontiers, 10(2):1451-1459.

Keywords: Educational Equity, Internet plus Satellite Live Broadcasting, Educational Community, Educational Resource

Correspondence to: Song Han, No.1 Middle School of Zhengzhou, Zhengzhou 450006, Henan, China. E-mail: zzyzhansong@126.com

Conflict of Interests: None.

(C) 2021 Insights Publisher. All rights reserved.

Creative Commons NonCommercial CC BY-NC: This article is distributed under the terms of the Creative Commons Attribution-NonCommercial 4.0 License (http://www.creativecommons.org/licenses/by$\mathrm{nc} / 4.0 /$ ) which permits non-commercial use, reproduction and distribution of the work without further permission provided the original work is attributed by the Insights Publisher. 


\section{Introduction}

$\mathrm{Q}$ UALITY and equity education has become an important issue in the global educational development. Emphasis on equality of opportunity is shifted onto equality of results and the quality of equity education is highlighted. To pursue results-oriented educational equity, Britain has conducted relevant educational reforms since 1997 and issued a series of texts of educational policies: Schools for Excellence (1997), The success in Learning (1999), Schools: Achieving Success (2001), Every Child is Important: for Children's Change, Higher Standards and Better Schools for All students: More Choices for Parents and Students (2005). Publication of these texts and implementation of the reform policies were aimed at reducing the impact of family background on education equity, alleviating unfairness and imbalances in education, and achieving results-oriented educational equity (Sahlberg, 2016).

To promote equality and high standard in education, Australia carried out a comprehensive reform of primary and secondary education with emphasis on both quality and equity early this century. Schools paid more attention to building up students' international competitiveness to meet social demands; Meantime, educational equity was linked with educational quality by strengthening the construction of educational infrastructure, prescribing a national uniform curriculum, and building a national intelligent school partnership to accelerate the advances of information technology in education (McGaw, 2006).

China has also been committed to the achievement of educational equity since the founding of the People's Republic of China. In 1949, China established an educational system for the people to promote universal education. Since the reform and opening up, continuous efforts have been made to upgrade educational equity from opportunity fairness to equality in results. The state promulgated the Guiding Opinions on Accelerating the Development of Education in the Central and Western Regions, the Notice of the Ministry of Education on Several Issues on Strengthening the Management of Basic Education, the Three-Year Action Plan for Preschool Education, the Rural Teachers Support Plan 2015-2020, the Nutrition Improvement Plan for Rural Students in Compulsory Education, the National Development Plan for Children in Poor Areas 2014-2020 and other policies (Yuan, 2019).

However, the long-standing urban-rural dual structure and the inter-regional imbalance of economic and cultural development in China impose profound impacts on the distribution of educational resources among regions, resulting in disparities between urban and rural schools in terms of educational investment, human resources, facilities, and teaching quality (Ma, 2008). To make the issue of quality and equity education more pressing, people's demand for high quality education is ever increasing, especially when the level of socio-economic development and people's awareness of the importance of education raised.

In the context of existing differences in educational levels, the construction of educational community is a critical path to the achievement of high-quality and balanced development of education (Chen, 2016). The integration of urban and rural edu- 
cation is not only the goal of balanced development of education, but also the solution to the inequality in education. Educational communities led by key schools with highquality educational resources in the region are applicable ways to implement the integrated development of urban and rural education. In this article, educational resources refer to the means which can be used to reach educational objectives, including school management mechanism, teachers' professional competence, curriculum design and teaching models.

As a key link in the global educational modernization, the application of information technology in education has become the orientation of educational development in various countries in building information ecology. The rapid development of satellite live broadcasting in China and the popularization of large-scale, high-quality, and lowcost live broadcasting technology as well as the robust advance of Internet technology make the spread of high-quality educational resources possible (MA, 2021). Educational communities aided by the technology of Internet plus satellite live broadcasting can break through traditional time and space restrictions and connects teachers from different schools and areas to carry out educational activities. This can not only promote the transmission and sharing of high-quality educational resources, but also brings new opportunities of development to those advantaged schools.

As one of the key schools in Henan Province, Zhengzhou No. 1 High School abounds in educational resources. To contribute to equal development of education in the region, No.1 Middle School of Zhengzhou started in 2006 to construct an educational community across time and space based on the technology of Internet plus satellite live broadcasting. This community involves 82 schools in 70 counties and cities in Henan Province, and a cumulative total of 1835 online classes, 119275 students and 11010 teachers since 2006. This paper first applies the resource dependence theory in the conceptual analysis of educational community and then present the practice of the educational community built by No.1 Middle School of Zhengzhou and its effectiveness in promoting regional educational equity based on the information technology.

\section{Resource Dependence Theory and the Regional Edu- cational Community}

Resource dependence theory was first put forward by Pfeffer and Salancik (2003) in The External Control of Organizations: A Resource Dependence Perspective and often employed in management and economics. It raised four important hypotheses: All organizations are dependent on the environment for their survival; The environment, to a considerable extent, contains other organizations; The resources one organization needs are thus often in the hands of other organizations; Legally independent organizations are therefore dependent on each other. Referring to this theory, we regard the regional educational community as a collective of educational units in cooperation based on resource dependence and set the goal of the community as integrating the educational resources in the region to promote the improvement of educational quality of all units in the region. 
The basic idea of regional educational community across time and space is to establish an operational system to enable the sharing of high-quality educational resources through the technology of Internet plus satellite live broadcasting so that the high-quality educational resources in developed areas can be extended to less developed areas, breaking through the boundaries of time and space, and prompting the balance of high-quality education among urban and rural schools. The value of such an educational community lies mainly in three aspects: The coverage of educational resources is no longer limited by teaching locations in traditional education and a new educational system and educational ecology can emerge; The reorganized educational resources can help promote the growth of both teachers and students. Third, disadvantaged schools can achieve significant development by employing the shared resources and disparities in educational levels among schools in the community can be alleviated.

\section{Research and Practice of the Construction of Educa- tional Community for Balanced Educational Devel- opment Based on Information Technology}

\section{Establishing an Educational Resource Sharing Plat- form Supported by Internet plus Satellite Live Broad- casting}

"Internet plus education" is an important component of China's "Internet plus" strategy and a powerful driving force in promoting the modernization of education. Satellite live broadcasting is a satellite transmission mode in which geostationary orbit satellites are used to transmit radio, television and multimedia data directly to small-scale organizations and families. Compared with traditional broadcasting and TV transmission mode, satellite live broadcasting has the characteristics of wide coverage, strong two-way data transmission, high-quality restoration of images and sound, simple reception, low cost, and user friendliness. The combination of Internet and satellite live broadcasting technology provides an excellent platform for multi-level and multi-directional transmission of educational resources, a successful example of integration of traditional educational resources and modern information technology.

In contrast, traditional educational resource platforms tend to be simple collectors of information and can only serve a school or a small group of schools, lacking in an effective sharing mechanism and the capacity of transmission region wide. In terms of contents, traditional platforms provide mainly texts, but few videos; The sources are typically limited to the self-supply of information from a small group of schools, not enough to form a complete teaching system; The resources are not students oriented. Thus, they cannot meet the demand for a wide range of knowledge. In terms of the technical capacity, traditional platforms have difficulty in meeting the requirement for 
data concurrency, information access and information storage in a large area, and lack long-term plans and sound foundation of infrastructure (Wu, 2017).

Based on extensive research, careful planning, and small-scale experiments, in August 2006, Zhengzhou No. 1 High School established the first distance education school specializing in sharing high-quality teaching resources in senior secondary education through live broadcasting, named Zhengzhou No. 1 High School Distance Education Campus. The distance education campus aims at resource sharing and common development, overcomes shortcomings of traditional modes, and presents a cutting-edge interactive teaching model supported by Internet plus satellite live broadcasting technology. With the aid of the network, the knowledge transmission and acquisition are no longer limited by time, place, and teaching environment. Teachers in the community can obtain high-quality educational resources through the platform at any time, which supplies opportunities to promote the balanced development of education in the region.

\section{Building an Educational Community Across Time and Space}

At present, the disparities between urban and rural areas in China's compulsory education are no longer caused by the gap in facilities, but rather by the differences in educational resources such as school management mechanism, teachers' professional competence, curriculum design, teaching models (An, 2019). Therefore, building an educational community across time and space to share excellent educational resources with schools weak in educational resources is an effective technological solution to the problem of educational inequity.

Zhengzhou No. 1 High School uses normal teaching classes as the live broadcasting classes. According to the school curriculum plan, each live broadcasting class is allocated an outstanding teacher of the subject. The chosen classes are broadcast live and received by the remote terminal classes in the community through the live broadcasting system. Each terminal class is staffed by teachers of various subjects as usual. Thus, this teaching model combines teaching of online outstanding teachers with meticulous offline tutoring. Meanwhile, all remote schools can also transmit their respective quality resources to the satellite live broadcasting system for open sharing. To ensure smooth development of the educational community, three priorities are highlighted as follows.

\section{Common Development of Teachers in the Community}

Teacher professionalism is a key determinant of teaching quality. To improve professional competence of all teachers in the community, live broadcasting class teachers and remote terminal school tutors conduct online teaching research and lesson preparation at scheduled time every week. Zhengzhou No. 1 High School regularly hosts seminars, academic exchanges, and high-level competence training. Other schools in the community also hold activities such as mutual visits of teachers, presentation of model lessons 
by outstanding teachers, and off-campus teaching research, to enable teachers to fully exchange teaching research results and make progress together.

\section{Integration of Online and Offline Teaching}

The prevalent "double-line" teaching, that is, mixture of online and offline teaching, are practically separate most of the time. Compared with the mixed online and offline teaching, the integrated online and offline teaching emphasizes integration or incorporation, which are the fundamental characteristics and core pursuit of the integrated teaching (Li, 2020). On No.1 Middle School of Zhengzhou Distance Education Campus, the online and offline teaching are fully integrated. Lecture teachers of the live broadcasting classes formulate teaching plans, conduct classroom teaching, and assign after-class tasks according to the curriculum and implementation plan of No.1 Middle School of Zhengzhou; Remote terminal class teachers organize classes, tutoring, and Q \& A, give feedback to lecturers, and discuss online with them to solve problems. The community has uniform examinations and assessments, and share teaching assessment results.

\section{Interactive Teaching Reforms}

Teaching reform is a multi-agent behavior involving teachers, schools, and society. In the educational community, No.1 Middle School of Zhengzhou is committed to providing practical and pertinent assistance for the disadvantaged schools in their teaching reforms and helps them convert extrinsic educational resources into intrinsic strengths. Schools in the community cooperate with one another in curriculum and teaching reform and share experience to improve teaching quality.

\section{Results of the Educational Community and Reflec- tions}

In this educational community supported by Internet plus Satellite live broadcasting, the educational resource distribution is focused on transmission of high-quality educational resources of advantaged schools to disadvantaged schools. Our goal is that students in the region can share educational resources equally and fairly.

After years of exploration, No.1 Middle School of Zhengzhou has created an effective model of educational resources sharing, well known for its practice of "one provincial key school helping other less advantaged school." A common curriculum system of the community is created by remote collaborative lesson preparation, teachertutor coordinated teaching and uniform assessment standards. Meanwhile, a channel of teachers' professional development is built by systemized activities such as joint online lesson preparation, offline teaching research seminars, presentation of excellent classes and high-level competence training. With efficient and regionwide resource sharing, a new educational ecology of multi-dimensional cooperation, mutual assistance and promotion has been formed. 
In addition, the technology of Internet plus satellite live broadcasting has enabled the school to formulate a working model of remote collaborative education. The major components of this model are integrated implementation of curriculum, teaching and assessment. Through integration of curriculum and teaching materials, the wide coverage of curriculum resources is realized; the working mechanism of combining teaching and research and the teacher-tutor teaching mode routinize the sharing of teaching resources; uniform assessment standards are reached through uniform test questions, examination organization, marking standards, and assessment feedback.

Using these two models, the educational community has greatly promoted the improvement of the overall educational quality and equity in the region and the development of No.1 Middle School of Zhengzhou.

First, the efficient model of educational resource sharing in the community has great advantage in regional poverty alleviation and has achieved good results. Since 2006, the community's educational resources have benefited 82 schools in 70 counties and cities in Henan Province, including 19 national key counties and 8 provincial key counties for poverty alleviation work.

Second, the construction of the educational community plays important roles in improving the educational level of numerous schools with weak foundation and promoting the equalization of education in the region. Since 2006, the number of classes and online teachers and students in the community has continued to grow every year. By 2018, there had been a cumulative number of 1,835 online classes, 119,275 students, and 11,010 teachers in this community, and $90 \%$ of these students came from remote counties and rural high schools.

Third, the two models help improve the learning quality of students in the region and their comprehensive competence. The school culture and learning methods of No.1 Middle School of Zhengzhou have gained wide acceptance among students in the remote terminal schools. After three years of learning and training in the community, they have made great progress in learning ability, thinking skills, and academic achievements.

Fourth, the two models help promote teachers' professional development and improve teachers' teaching and research level. Teachers of the live broadcasting classes have set extremely high standards for themselves because of their special roles. In addition, hosting remote collaborative teaching and research every week and participating in teaching seminars encourage them to raise their professional levels. Teachers selected as live broadcasting lecturers face a larger teaching platform and stricter assessments, which motivates them to make continuous progress. As a result, many of them have become municipal and provincial teaching role models. The tutors of the remote terminal classes have improved their professional competence and teaching and research level greatly by working alongside teachers of live broadcasting classes. Young teachers have attained particularly rapid growth in the community. More than $80 \%$ of those teachers with less than five years of teaching experience have received commendations in the official selection of high-quality courses, subject research, or theses after having 
worked and trained in the community. This has further stimulated overall progress of teachers in remote terminal schools.

Finally, the practice of educational community stimulates education and teaching reform aiming at developing students' comprehensive competence. To improve the results of classroom teaching and cultivate students' high order thinking abilities, No.1 Middle School of Zhengzhou initiated a teaching reform named self-directed learning in the community in 2009. Self-directed learning requires students to use their initiative to find, analyze and solve problems in study and to understand the learning process and key elements of knowledge through inquiries. It is a counter to the traditional teacherdominated teaching model. Teachers and students at all schools in the community participated actively in this reform and gave effective feedback so that the reform led by No.1 Middle School of Zhengzhou could be conducted smoothly and received good results in the community. Self-directed learning fundamentally changes students' learning habits and skills. The Theory and Practice of Self-Directed Learning, a study based on the reform won the first prize of Henan Basic Education Teaching Achievement Award in 2014. Zhengzhou No. 1 High School, with its effort to build the educational community, is well recognized by other schools, students, parents, and society.

Despite the achievements, the school is reflecting on how to make better use of information technology and the educational community to make more contributions to equalization of education in the region. Several suggestions are proposed for future experiment and exploration. Technically, a switching function should be added to live broadcasting so that real-time screen switching can be conducted in live broadcasting and students at remote terminal schools have the opportunity to ask questions and discuss with lecturers online; The online tutoring and Q \& A platform should be improved to ensure that teachers can provide effective tutoring for students in remote rural areas in time. To further improve educational quality of the schools in the community, the contents of the live broadcasting classes should be expanded to cover more subjects and activities such as morality, art festival, club activities and school-opening ceremony. Moreover, new initiatives should be introduced to enrich the practice of resource sharing. For example, students should be encouraged to make personal friends in other schools in the community and exchange visits to enhance mutual understanding. All in all, our vision is to build a high-tech and sustainable educational community with the goal of common development of all students.

\section{References}

An, F.H. (2019). The construction of urban and rural teachers' teaching community support- ed by information technology. E-Education

Research, 2019(7):70-75 + 83. DOI: 
Han (China). Educational Community on Internet and Satellite Live Broadcasting.

https://doi.org/10.13811/j.cnki.eer.2019.07.0

09

Chen, H.Y. (2016). Establishing educational community to promote the equalization of high-quality educational resources (Master's thesis). Tianjin University. Available at: https://kns.cnki.net/KCMS/detail/detail.aspx ?dbname $=$ CMFD201801\&filename $=101706$ 1103.nh

Li, Z.T. (2020). Basic education in the postepidemic era: A new era of double line integrated teaching. Journal of the Chinese Society of Education, 2020(5):5.

Ma, A.P. (2021, July 19). Satellite Internet: Low-cost challenge in the field of high technology. Science and Technology Daily. P.6

Ma, Y.Y. (2008). An economic perspective of the unbalanced development of general education between urban and rural areas and among regions in China (Master's thesis). Fudan University. Available at: https://kns.cnki.net/KCMS/detail/detail.aspx ?dbname $=$ CMFD2009 \& filename $=20090184$ 12.nh

McGaw, B. (2006). Achieving quality and equity education. Committee for Economic Development of Australia (CEDA), 3.

Pfeffer, J. \& Salancik, G.R. (2003). The external control of organizations: a resource dependence perspective. Social Science Electronic Publishing, 23(2):123-133.

Sahlberg, P. (2016). The global educational reform movement and its impact on schooling. In K. Mundy, A. Green, B. Lingard, \&A. Verger (Ed.). The Handbook of Global Education Policy (pp.128-144). Wiley Online Library. DOI:

https://doi.org/10.1002/9781118468005.ch7

Wu, S.Y. (2017). Construction of educational resource sharing platform in counties in the Internet plus era. Journal of Teaching and Management, 2017(6):43-46.

Yuan, Z.G. (2019). The Chinese model of educational equity. Journal of the Chinese Society of Education, 2019(9):1-5. 